\section{ORAL HEALTH THAT HELPS PROTECT THE PLANET}

Coming soon from premium oral

hygiene brand TANDEX is the WOODI interdental brush.

The WOODI has a handle made from FSC-certified birchwood and is supplied in a recyclable cardboard box. It comes in six sizes, each identified by a unique colour.

The WOODI is part of the TANDEX commitment to respect the environment.
Only food-approved raw materials are used to make its products, which are manufactured using sustainable energy sources, to reduce the carbon footprint.

TANDEX believes that oral health products should help protect the planet as well as 'keep you smiling. To find out more, visit the website today.

For more information on Tandex's range of products, visit https://tandex.dk/.

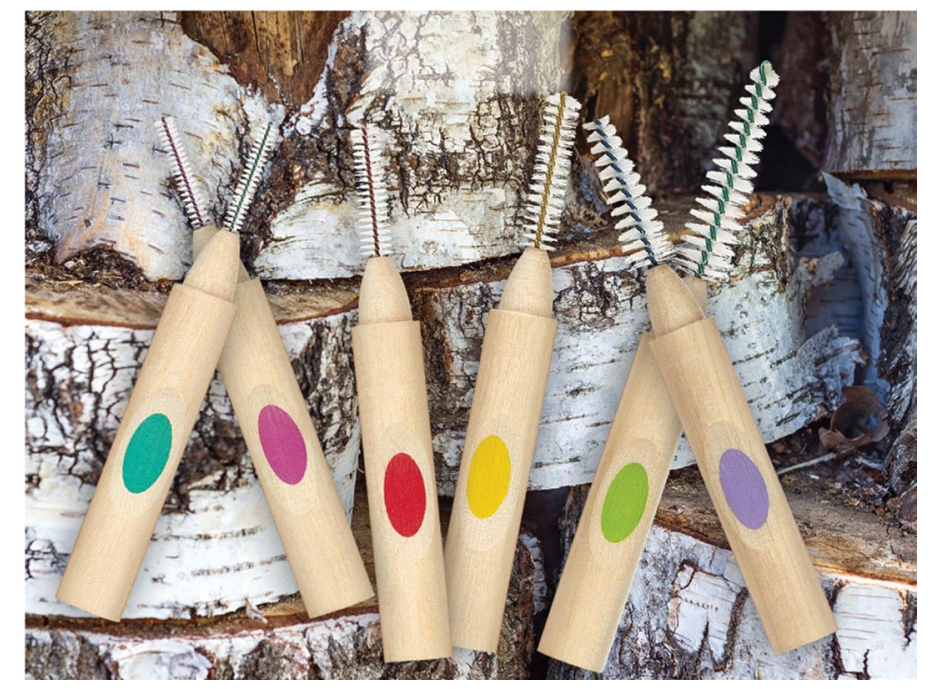

\title{
ENABLING DISABLED PEOPLE TO PLAN PERSONALISED ASSISTANCE
}

The WelcoMe App enables patients with a disability to plan personalised assistance when they visit a dental practice.

The London Centre for Cosmetic Dentistry is the first dental practice in the UK to install this technology.

Using the app, disabled patients build and share an accessibility profile and can inform the practice when they are attending and their specific needs. Once they are en route, the practice can track where the user is and be at the door ready to welcome and assist where necessary.

WelcoMe businesses receive real time training and clear guidance on how to interact with customers directly related to their needs, disabilities or conditions they disclose and in return disabled
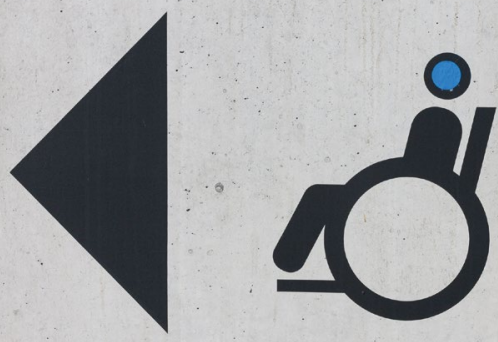

visitors are provided with key up to date accessibility and assistance information. The WelcoMe app is supported by leading charities, such as RNIB, Alzheimer's Society and Deafblind UK, and caters for a wide range of disabilities, including deafness, autism, dementia, visual impairment and stammering.

For more information on WelcoMe visit www.wel-co.me, email caro@wel-co.me or call 07449451325.

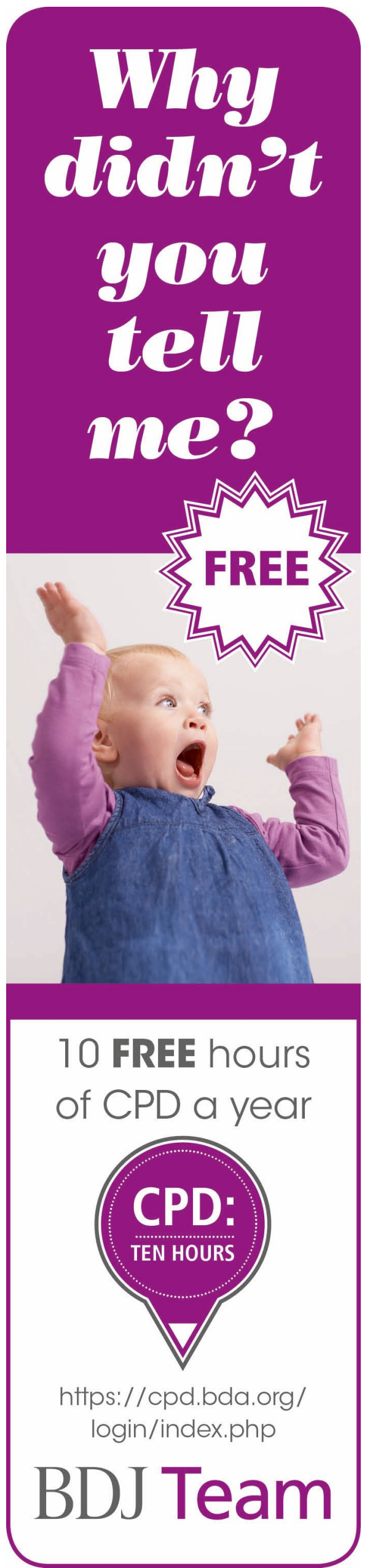

